10IKC-212

\title{
SULFIDE INCLUSION RE-OS AGES AND CARBON, NITROGEN OF DIAMONDS FROM THE MUROWA KIMBERLITES: IMPLICATIONS FOR ZIMBABWE CRATON EVOLUTION
}

\author{
Gaillou* E ${ }^{1}$, Shirey SB ${ }^{1}$, Bulanova GP ${ }^{2}$, Marks B. ${ }^{2}$, Smith $\mathrm{CB}^{2}$, Wang $\mathbf{J}^{1}$, Kohn $\mathrm{SC}^{2}$, Walter $\mathbf{M J}^{2}$. \\ ${ }^{1}$. Department of Terrestrial Magnetism, Carnegie Institution of Washington, Washington D.C., USA \\ ${ }^{2}$. School of Earth Sciences, University of Bristol, United Kingdom \\ *corresponding author (asteriee@yahoo.fr)
}

\section{INTRODUCTION}

Diamonds from the Zimbabwe craton have received the least attention of all the major diamond producing cratons. The potential for an extremely depleted, old continental lithospheric keel to the Zimbabwe craton is suggested by the low Os isotopic compositions of crustal chromites, an average Re-Os model age for peridotites of 3.2 $\mathrm{Ga}$, the dunitic character of peridotite xenoliths and silicate inclusions in diamonds, and high seismic velocities. We have begun a thorough ReOs study of sulfides and chromite inclusions in Murowa diamonds to establish their composition, paragenesis, and age, and to place diamond formation in context of lithospheric mantle depletion. A significant question is the relationship of the Zimbabwe craton keel to that of the adjacent Kaapvaal lithospheric keel to the west and south.

\section{SAMPLES AND METHODS}

We selected 13 diamonds containing sulfide inclusions (12 from Murowa, 1 from Sese) from a suite of 280 diamonds from Zimbabwe. Each diamond selected contains inclusions within rosette fractures, which are typically sulfide. The inclusions were located close to core of the diamond, with no link to the surface. Sulfides are smaller in size than typical eclogitic sulfide inclusions that have been used previously for ReOs dating, therefore making the chemistry procedure and the actual measurement a challenge.

The diamonds were cut by laser and polished along two parallel dodecahedral planes so that central parallel plates were made. The internal structure of the diamonds was studied by CL imaging using an ELM-3R luminoscope setting at the Smithsonian Institution. Infrared (IR) spectra were acquired with a Bio Rad (Digilab) Excalibur FTS 3000 spectrometer with a microscope attachment, using a resolution of 4 $\mathrm{cm}^{-1}$ and a beam of section $250 \times 250 \mathrm{im}$. Several measurements per diamond were made in order to study the heterogeneity of $\mathrm{N}$ distrubution. $\mathrm{N}$ content as seen by IR was determined using the software developed by J. Chapman (Rio Tinto), and applying Boyd et al.'s coefficients (1994, 1995). Carbon isotopes $\delta^{13} \mathrm{C}$ were determined with a Cameca ims $6 \mathrm{~F}$ secondary ion mass spectrometer (SIMS), while $\mathrm{N}$ and $\delta^{15} \mathrm{~N}$ were measured with a Cameca 50L NanoSIMS both at Carnegie Institution.

\section{RESULTS}

Infrared spectra revealed that all the diamonds were type IaAB, with small to high amount of $\mathrm{H}$. Depending on the sample, the amount of A- and B-aggregates ranges from 40 to 


\section{$10^{\text {th }}$ International Kimberlite Conference, Bangalore - 2012}

800 ppm, with an aggregation state (\%IaB) of 23 to $78 \%$ (Fig. 1). Normal zoning of the amount of $\mathrm{N}$ aggregation is sometimes found inside a single sample (Fig. 1): closer to the core of the diamond, the aggregation state is higher. When zoning is present, $\mathrm{N}$ and $\mathrm{H}$ are seen in higher amount in the core zone of the diamond. Cathodoluminescence reveals a typical one or two step growth history, with either simple continuous growth or with the presence of an older core in which the sulfide inclusion is located (Fig. 2). A typical blue luminescence is usually observed when there is emission, most likely related to the blue band (dislocation related) or to the N3 center (defects involving $3 \mathrm{~N}$ around a vacancy). Three diamonds present a CL emission activated by the presence of platelets.

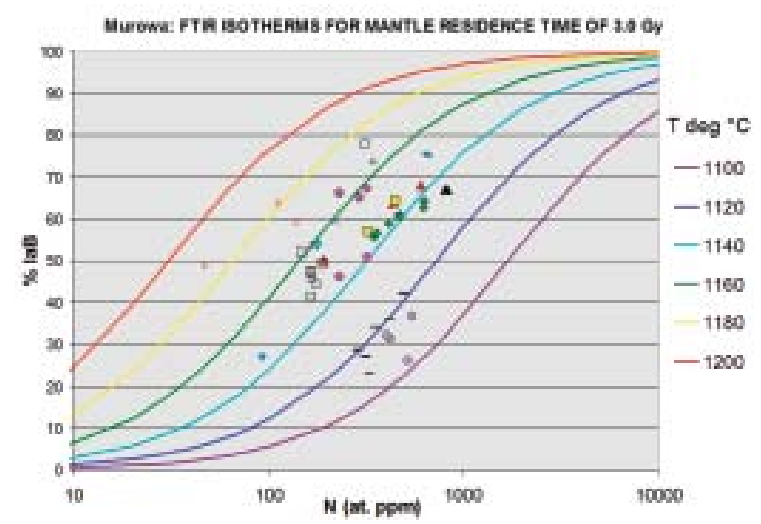

Fig. 1: Sese and Murowa FTIR isotherms for a mantle residence time of $3 \mathrm{Ga}$. Same symbols mark analyses in different areas of the same sample.

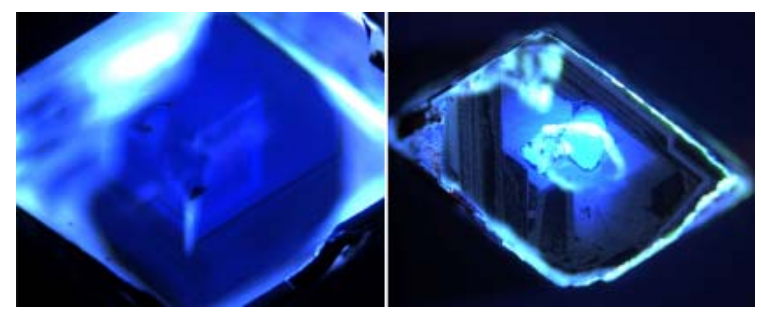

Fig. 2: Cathodoluminescence images of 2 diamonds from Murowa. Left: continuous octahedron growth (sample Mur185, 3mm wide diagonally). Right: two-stepped growth, with an ancient core, and a younger rim in which emission from the so-called platelets can be observed (sample Mur222, $2.2 \mathrm{~mm}$ wide diagonally).
C isotope composition acquired by SIMS ranges typically from -2.5 to $-5.8 \%$ o, except for one sample which has significantly lighter values around $-10 \%$. This main value around $-5 \%$ is consistent with a dominant P-type paragenesis for Murowa and Sese diamonds (Bulanova et al., this session). One diamond with carbon isotope signatures at $-10 \%$ more likely is of the rare Etype. While there is no zoning in the supposed Etype diamond, the P-type diamonds show small $\mathrm{C}$ isotope variations from core to edge of around $1 \%$, but without typical grading (the core could be lighter or heavier than the edges). Heterogeneity of $\mathrm{N}$ distribution is better revealed by SIMS than by FTIR: instead of a large volume, a more local analysis $(120 \times 120 \mathrm{x} \sim 1 \mu \mathrm{m})$ is obtained. Some samples present in fact a strong zonation of $\mathrm{N}$, with virtually no $\mathrm{N}$ on the edge, with a lot on their core (ex: from 0 to $700 \mathrm{ppm}$ for one sample). $\delta^{15} \mathrm{~N}$ were relevant only when $\mathrm{N}$ content was $>100 \mathrm{ppm}$. The range of $\delta^{15} \mathrm{~N}$ varies from +8 to $-18 \%$ (average error $=3 \%$ ) from sample to sample, and with almost no variation for all samples except one (for which $\delta^{15} \mathrm{~N}=6$ to $15 \%$ ). These values are all consistent with peridotitic values reported in Cartigny (2005).

Re-Os analyses are still under investigation at the time this abstract was drafted.

\section{DISCUSSION \& CONCLUSION}

The initial analyses of one Murowa sulfide inclusion reported at 9IKC (Smith et al. 2009), are among the lowest ${ }^{187} \mathrm{Os} /{ }^{188} \mathrm{Os}$ ever measured for a sulfide inclusion in diamonds (0.10507). If such isotopic compositions are representative of the sulfides from Murowa diamonds for which analysis are currently underway, then this would establish the Zimbabwe craton as recording different processes from the Kaapvaal during time of diamond formation. The Kaapvaal craton appears initially depleted in sulfur after which an eclogitic component was added during craton 


\section{$10^{\text {th }}$ International Kimberlite Conference, Bangalore - 2012}

collision at $3.0 \mathrm{Ga}$. The Zimbabwe craton instead preserves its initial depletion/diamond formation record.

If we take this maximum age of formation for diamond (i.e. 3.0 Ga), diamond formation temperatures determined from $\mathrm{N}$ content and aggregation state are in the range of 1100 to $1200^{\circ} \mathrm{C}$, consistent with temperatures obtained by Bulanova et al. (2012, this session) (Fig. 1). Each diamond has FTIR analyses plotting along the same isotherm, marking a depletion of $\mathrm{N}$ with growth time, under similar thermal conditions.

\section{ACKNOWLEDGEMENTS}

Rio Tinto PLC is acknowledged for provision of diamond samples and analytical support. Financial support was provided by NSF proposal No 1049992.

\section{References}

Boyd, S.R., Kiflawi, I., Woods, G.S. (1994) The relationship between infrared absorption and the A defect concentration in diamond. Philosophical Magazine B, 69, 1149-1153.
Boyd, S.R., Kiflawi, I., Woods, G.S. (1995) Infrared absorption by the B nitrogen aggregate in diamond. Philosophical Magazine B, 72, 351-361.

Bulanova G.P., Marks A., Smith C.B., Kohn S.C., Walter M.J., Gaillou E., Shirey S.B.. Trautman R. and Griffin B.J. (2012) Diamonds from Sese and Murowa kimberlites (Zimbabwe) - Evidence of extreme peridotitic lithosphere deplation and TiREE metasomatism. 10th International Kimberlite Conference Extended Abstract No. 10IKC-220

Cartigny P. (2005) Stable isotopes and the origin of diamond. Elements, vol. 1, 79-84.

Hauri,E.H., Wang J., Pearson D.G., Bulanova G.P. (2002) Microanalysis of d13C, d15N, and N abundances in diamonds by secondary ion mass spectrometry. Chemical Geology 185, 149- 163.

Smith C.B., Pearson, D.G., Bulanova, G.P, Beard, A.D., Carlson, R.W., Wittig, N., Sims, K., Chimuka L., Muchemwa E., 2009. Extremely depleted lithospheric mantle and diamonds beneath the southern Zimbabwe Craton. Proc. 9th Int. Kimberlite Conference, Lithos, 112S (1-4): 1120-

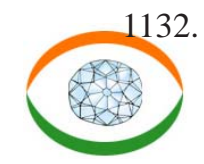

